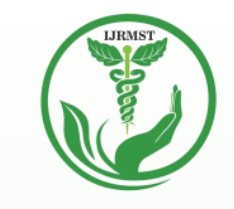

INTERNATIONAL JOURNAL OF RESEARCH IN MEDICAL SCIENCES \& TECHNOLOGY

e-ISSN:2455-5134; p-ISSN: 2455-9059

\title{
DEVELOPING AN INTEGRATED MODEL BASED ON NAÏVE- BAYES AND DECISION TREE ALGORITHMS IN THE EARLY DETECTION AND DIAGNOSIS OF CARDIAC DISEASES
}

\section{Ishaan Gupta}

Bal Bharati Public School, Pitampura, New Delhi

Paper Received: 05 ${ }^{\text {th }}$ August, 2021 ; Paper Accepted: 04 ${ }^{\text {th }}$ October, 2021 ;

Paper Published: 16 $6^{\text {th }}$ October, 2021

DOI: http://doi.org/10.37648/ijrmst.vl li02.009

How to cite the article:

Ishaan Gupta, Developing an Integrated Model Based on Naïve-Bayes and Decision Tree Algorithms in the Early Detection and Diagnosis of Cardiac Diseases, IJRMST, July-December 2021, Vol 12, 107-114, DOI: http://doi.org/10.37648/ijrmst.v11i02.009

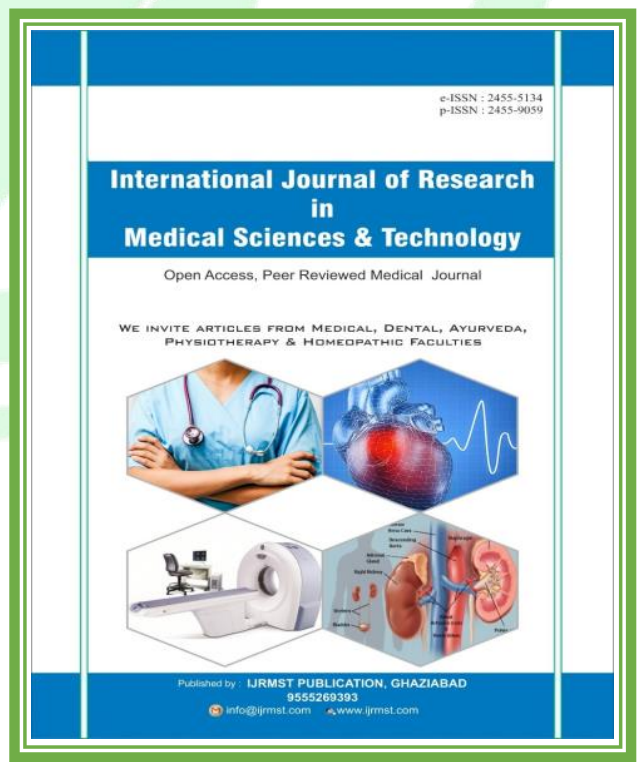




\section{ABSTRACT}

The extraction of concealed information from the enormous data sets is information mining, and it is otherwise called Knowledge Discovery Mining. It has many assignments. One of them utilized here is prescient errands that use a few factors to foresee obscure or future upsides of another dataset. The significant medical issue that influences countless individuals is a coronary illness. Except if it is treated at a beginning phase, it causes demise. Today, the Healthcare business creates an enormous measure of perplexing information about the patients and assets of the emergency clinics, from a period where there has been no good spotlight on compelling examination instruments to find connections in communication, particularly in the clinical area. The methods of mining information are utilized to examine rich assortments of details according to alternate points of view and infer useful data to foster analysis and anticipating frameworks for coronary illness dependent on prescient mining. Various preliminaries are taken up to look at the exhibitions of different information mining procedures, including Decision trees and Naïve Bayes calculations. As proposed, the peril factors are pondered, Decision trees and Naïve Bayes are applied, and the show of their finding have been investigated by the UCI Machine Learning Repository I,e WEKA instrument. Thusly, the Naïve Bayes beats the Decision tree.

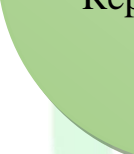

\section{INTRODUCTION}

Information Mining is investigating enormous informational indexes to retrieve it from previous task, new information, affiliations that are difficult to see with mathematical strategies. It has very significance for giving analysis and comprehension of clinical data. It is a vital stage in finding information bases. It contains an iterative arrangement and is achieved utilizing expectation, grouping, affiliation, and more examination even though applying information mining in diagnosing infection is valuable, which can work on the presentation and gives dependable precision. It is carried out as an electronic application. The current attempt aims to find the part of medical services by AI strategies and propose the mechanized delve nosing. Health associations' decrease cost, achieving PC based information. The administrations that fuse patients records and there are many undertakings of mining the information they are to be specific prescient and expressive assignments which comprise of many branches were prescient errands contains order, Prediction and time series examination. Were as the detailed investigation including the relationship of the information bunching the information, and afterwards, the latter is the synopsis of 


\section{VOLUME: 12, JULY-DECEMBER 2021}

the informational indexes present. Here we consider the prescient examination of mining the information where we foresee proactive investigation measure has many advances which in particular referenced in the above figure Were first there is a need of the characterizing an undertaking is an initial step. There is a need for an assortment of information. Next to the investigation of the report, the insights are created dependent on the examination, and later it is displayed. Ultimately it is sent these are the different strides to the study of the Predictive Process.

The acknowledgement of coronary illness from an assortment of factors or signs is a complex issue that isn't liberated from bogus theory frequently go along with unfixed impacts. In this manner, the attempt to utilize data and comprehension of incessant subject matter experts and clinical screening information of patients gathered in data sets to work with the analysis cycle is viewed as a significant choice. However, long important administrations at reasonable expenses is a considerable requirement experienced by the medical care associations. Effective quality assistance indicates the precise analysis of patients and giving proficient treatment. Poor clinical choices might prompt calamities and consequently are rarely engage. Also, it is fundamental that the clinics decline the expense of clinical tests. Suitable PC based data or potentially choice emotionally supportive networks can help accomplish clinical trials at a decreased cost. The heart is an essential piece of the body. It is caused by hindering coronary arteries, which is brought about by testimony of fat on the mass of internal course and because of cholesterol fabricate. Identifying the significant dangers from patients of heart to distinguish the degree of hazard factors in assisting patients with saving their life ahead of time. 


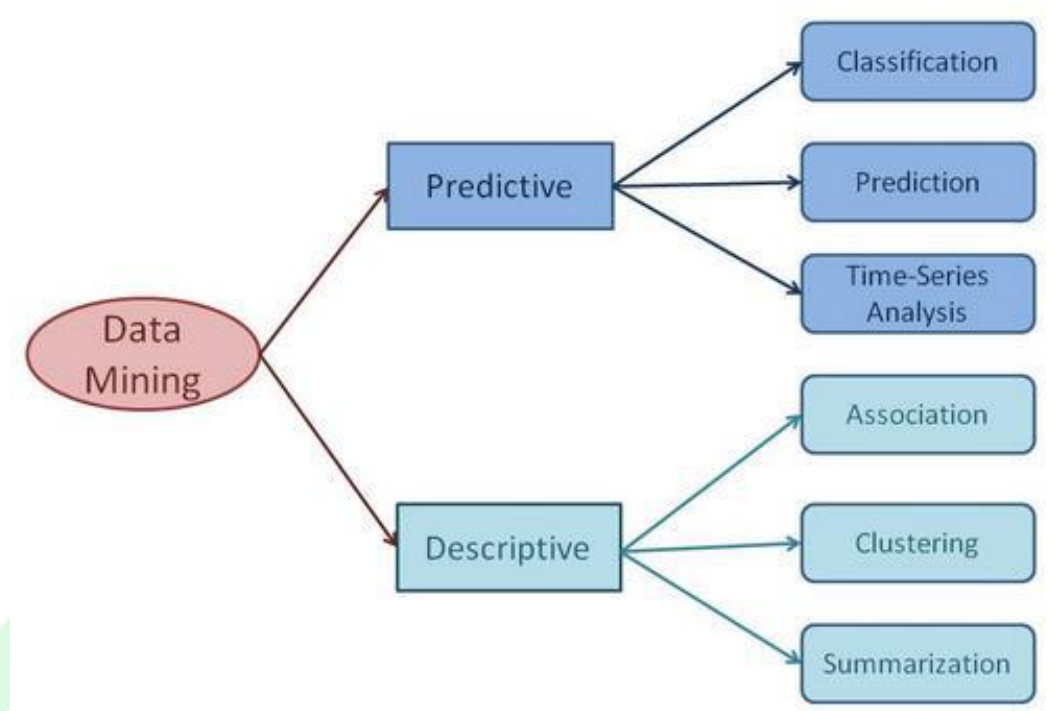

Figure :1 General architecture of datamining tasks

\section{Predictive Analytics Process}

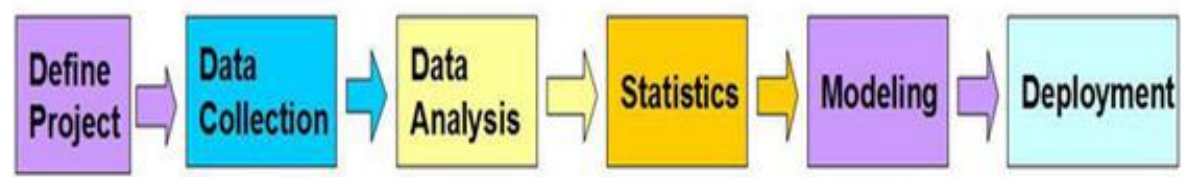

Figure :2 General Predictive analysis Process

\section{TASK EXPLANATION}

Data extraction is the furthermost essential and region with discovering important data from colossal informational indexes. It has developed additional well known in the medical services area as there is a need for capable and legitimate meth0d0logy for recognizing new significant information from the healthy area. Instruments of information mining perform an investigation of information and reveal designs. It is a more advantageous device to help doctors recognise the sickness by getting data regarding patients' informational index. There is a need for clinical pardoners to anticipate before it shows up or happen in patients. As the colossal measure of data is delivered in clinical affiliations yet, this isn't valuable. There is a shortfall of effective examination techniques to associations and examples in useful consideration data. 


\section{ISSUE STATEMENT}

The fundamental driver of death overall is considered by coronary illness. Clinical Practitioners Generated information with an abundance of concealed data present and not appropriately utilized adequately for the forecast. people pass on having gifted manifestations that did not take into consideration.

\section{OBJECTIVE OF THE PROJECT}

The primary objective of this work is to figure attainable coronary failure from the patient's dataset utilizing strategies of information mining and figure out which module gives the top level of the right forecast for the analysis.

The vital goals are:

1. High precision is gotten.

2. To help the medical care sector\&

3. Pace of death is decreased.

\section{EXTENT OF STUDY}

The extent of the task is that the well-being be concerned industry assembles colossal measure of insights and made viably mined to find stowed away data

$$
P(X \mid C i)=\prod_{k=1}^{n} P(x k \mid C i)
$$

$=\mathrm{P}\left(\mathrm{x} 1 \mid \mathrm{Ci}_{i}\right) \mathrm{x}\left(\mathrm{x} 2 \mid \mathrm{Ci}_{i}\right) \mathrm{x} \ldots \mathrm{P}(\mathrm{xm} \mid \mathrm{Ci})$.

\section{STRATEGIES AND MATERIAL}

Decision Trees

A decision tree is a straightforward depiction of older models. For this segment, underestimate that all commitment clarification has fixed disconnected space, and there is an independent reason exterior called understanding. Every one element of the circle of the classifying is known as a division. Its action tree is a pecking order wherein every homegrown join is measured with an endeavour abnormality. The crescent coming from an expanding market with a put in quality are named with every one of the potential upsides of the objective or usefulness characteristic or the curve led to a subordinate decision hub on a disparate info trait. Each piece of paper of the positioning is marked with a gathering of understudies or a perspective giving out unrivalled than the program. 


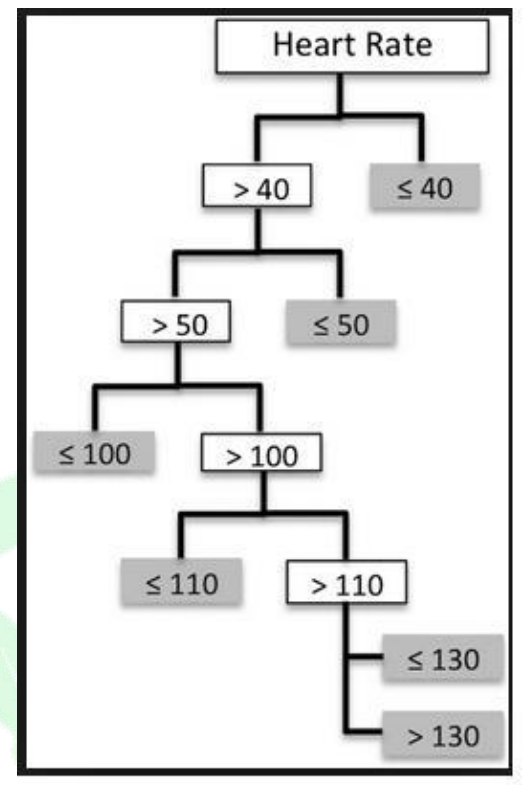

Decision Tree for prediction of heart disease

\section{EXISTING SYSTEM}

The current structure uses the choice tree framework. These are non-parametric learning techniques used for portrayal. What's more, it is one of the most remarkable strategies in grouping. It builds the models as trees structure. Here datasets break into little sets simultaneously, a related choice tree is framed. It contains both numeric and text values. It is taken dependent on the traits.

Downsides of Existing structure

1. Significant expense.

2. Hard to deal with non-numeric information.

3. Many branches are hard to comprehend with trees.
4. Drawn-out.

5. It is less master

6. Time burning-through.

\section{PROPOSED SYSTEM}

This Proposed work is to develop a model for estimating the set base on specific ascribes. The work applies the accompanying calculations: Naive Bayes calculation to order and foster a model to conclude coronary failures in the patient informational collection from clinical practiti0ners. Naive Bayes is considered as the probability classifier whose model is autonomous. Overall, it accepts that presence or nonattendance of some other trademark prepared to work in administered learning way. 


\section{VOLUME: 12, JULY-DECEMBER 2021}

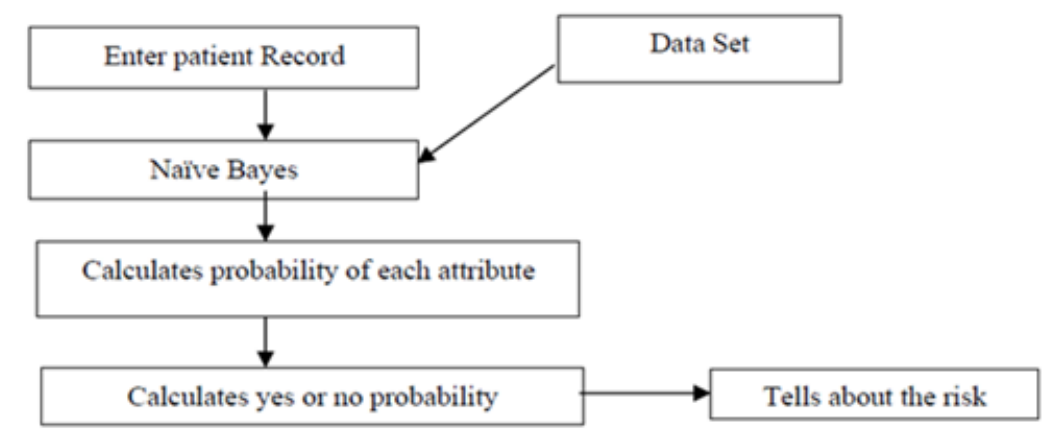

Figure:3 Architecture of Prediction of Heart disease

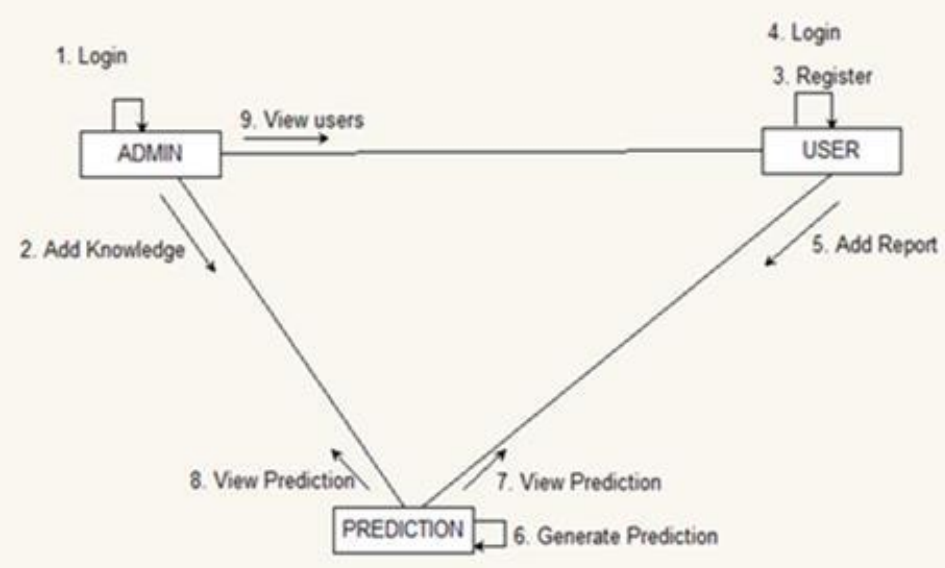

Great conditions

1. Successful of cost

2. From the given before can anticipate credits, coronary illness.

3. raised accuracy in assumption.

4. Assists prosperity with portioning in expecting the disorder earlier.

5. Effectively handle huge measure of information.
6. Handles truthful and discrete information.

\section{CONCLUSION}

Information mining procedures are utilized to discover the secret information for making it helpful. Hence, the objective is met by using the patient's educational assortment of characteristics. Without much of a stretch, we can foresee the conceivable coronary failure from the 


\section{VOLUME: 12, JULY-DECEMBER 2021}

given informational index of the patients... drove many meetings of preliminaries with the equivalent datasets in UCI Machine Repository I,e.WEKA devise. An information list of some records with a foreordained number of attributes is used, and the outcome reveals that the Naïve Bayes beats the Decision Tree.. Guess of the coronary illness will be assessed by the outcome delivered from it. Improvement is made to expand its consistency and proficiency.

\section{REFERENCES}

[1]. Divya Kundra, Er. Navpreet Kaur, " Review 0n prediction system for heart diagnosis using Data Mining Techniques, IJLRET ISSN: 2454- 50, ISSN: 2454-5031

[2]. Ms.Rupali R.Patil, "Heart Disease Prediction System using Naïve Bayes and Jelinekmercer smoothing", International Journal of Engineering Science and C0mputing, March 20162680 http://ijesc.org/ International J0urnal Advanced Research in Computer and Communication Engineering Vol. 3, Issue 5, May 2014.

[3]. K.Manimekalai, "A Review on Prediction of Heart Diseases by C0mparing Risk Factors in Data Mining", IJCSIT, ISSN:0975- 9646, Vol 7(1), 2016, 396-398.

[4]. B.Venkatalakshmi, M.V.Shivashankar, "Heart Disease Diagn0sis Using Predictive Data Mining", IJIRSET, Vol 3, March 2014, ISSN : 2319-8753

[5]. Hlaudi Daniel Masethe, Mosima Anna Masethe, "Prediction of Heart Disease using Classification Alg0rithms", Proceedings of the WOrld Congress on Engineering and Computer Science 2014 Vol II WCECS 2014, 22-24 October, 2014, San Francisco, USA.

[6]. Nidhi Bhatla and Kiran Jyoti, "An Analysis of Heart Disiease Prediction using Different Data Mining Techniques", International Journal of Engineering Research \& Technology (IJERT), ISSN: 2278- 0181,Vol. 1 Issue 8, October - 2012

[7]. Abhishek Taneja, "Heart Disease Prediction System Using Data Mining Techniques", Oriental Journal of computer Science \& Technology , An International Open Free Access, Peer Reviewed Research Journal.

[8]. Abhishek taneja, Heart Diseiase Prediction System Using Data Mining Techniques, Oriental Scientific Publishing Co., India, 2013. 